\title{
Connotation and Development of Energy Storage in Energy Chemical Engineering Education
}

\author{
Yu Tan, Kexin Liang, Yanqing Li \\ North China Electric Power University, Baoding, China \\ Email: lucifertan@163.com
}

How to cite this paper: Tan, Y., Liang, K. X., \& Li, Y. Q. (2020). Connotation and Development of Energy Storage in Energy Chemical Engineering Education. Open Journal of Social Sciences, 8, 522-528. https://doi.org/10.4236/jss.2020.83045

Received: March 15, 2020

Accepted: March 28, 2020

Published: March 31, 2020

\begin{abstract}
In the context of the construction of national "double first-class" universities, the implementation of energy chemistry engineering subject teaching reform has an important role in improving teaching quality and subject influence. Taking energy storage courses as an example, integrating social needs into courses and carrying out goal-driven teaching can enable students to continuously improve their comprehensive analysis capabilities, enhance engineering awareness, and achieve an orderly transition from theoretical knowledge to practical applications.
\end{abstract}

\section{Keywords}

Energy Chemical Engineering, Energy Storage

\section{Introduction}

The major of Energy Chemical Engineering was newly founded in 2011. Energy Chemical Engineering belongs to a brand-new major. Previously, it only covered a little in the major of Chemical Engineering and Technology, mainly focusing on how to use energy and cause less damage to nature. The main research directions as clean energy conversion, coal chemical industry, petrochemical industry, gas and natural gas engineering, environmental catalysis, green synthesis, utilization of new energy and chemical conversion of environmental chemical industry. As an important branch of chemistry, energy chemistry is an important scientific and technological foundation for mastering the comprehensive utilization of coal, understanding non-coal mine energy, popularizing new energy and renewable energy knowledge, and realizing the scientific utilization and sustainable development of energy (Peng \& Ye, 2020). It uses the theory and 
technology of chemistry and chemical industry to solve the problems of energy conversion, energy storage and energy transmission to better serve the human economy and life. Chemical changes are accompanied by changes in energy, and the essence of energy use is the conversion process of energy forms. Energy chemistry realizes the conversion and storage of energy directly or indirectly through chemical preparation materials technology due to its chemical reaction. This specialty carries out basic and applied basic research on the optimal utilization of fossil resources, focusing on solving major issues such as the development of high-efficiency new catalysts and their industrial scale-up, research and development of high-efficiency, low-cost, large-scale, and environmentally friendly non-petroleum alcohol ether ester synthesis process routes, preparation, storage and conversion of clean energy. Develop new supercapacitors based on liquid phase reactions, develop new materials for lithium-ion batteries, fuel cells and solar cells. This major actively responds to the urgent needs of China and the world for the upgrade of traditional energy sources, renewable energy and new energy materials, and aims to cultivate the scientific use and sustainable development of traditional energy and green renewable energy. Leading talents with outstanding contributions, cultivate basic theories, basic knowledge and basic skills in the conversion and utilization of chemistry and energy, cultivate high-level specialized application talents with good scientific literacy, solid foundation, broad knowledge, innovative spirit and international vision. With scientific research, production design and technical management in the fields of coal industry, power industry, petroleum and petrochemical industry, biomass conversion and utilization industry engaged in low-carbon energy cleaning, renewable energy utilization, energy efficient conversion, chemical energy evaluation and other fields ability. Main courses are Inorganic Chemistry, Analytical Chemistry, Organic Chemistry, Physical Chemistry, Principles of Chemical Engineering, Mechanical Fundamentals of Chemical Equipment, Engineering Drawing, Chemical Instruments, Coal Chemistry, Chemical Engineering Thermodynamics, "Chemical Reaction Engineering, Chemical Separation Engineering. The main professional courses are Energy and Chemical Technology, Petroleum and Natural Gas Processing Engineering, Coal Chemical Clean Technology, Biomass Conversion Technology, Chemical Process Design, Chemical Energy Saving Technology, Chemical Safety and Environment etc. The training objective of this major emphasizes the characteristics of thick foundation, wide major, high quality, solid chemical and chemical basic knowledge and energy chemical engineering professional knowledge so that graduated students can adapt to fields involving chemistry, chemical engineering, traditional and new energy processing etc. Wide demand. graduate work areas include coal chemical industry, natural gas chemical industry, power plant chemical comprehensive utilization industry, bio-energy chemical industry, solid waste comprehensive treatment industry, petroleum processing industry, petrochemical industry, natural gas industry, urban gas, analysis and testing, catalyst production and R \& D industry. You can engage in design, scientific research, technical 
management, etc. in these industries or continue your studies. Also Chemical Engineering and Technology, Chemical and Pharmaceutical, Chemical Engineering and Industrial Biological Engineering, Energy and Environmental System Engineering, Energy Engineering and Automation, Energy Power System and Automation is a similar course. As of 2020, a total of 58 colleges and universities in mainland China have opened this major, including first-class undergraduates and second-level undergraduates.

The energy and chemical undergraduate major established by North China Electric Power University in 2011 will focus on "coal chemical", aiming to cultivate the basic knowledge of energy chemical engineering, basic theory and strong application research and technology development capabilities and good science accomplished and adaptable senior specialized talents who have obtained basic training from engineers.

\section{Meaning of Energy Storage}

Energy storage mainly refers to the storage of electrical energy. Energy storage is a term in petroleum reservoirs, which represents the ability of reservoirs to store oil and gas. Energy storage is not an emerging technology, but it has just emerged from an industry perspective and is in its infancy. So far, China has not reached a level similar to that of the United States and Japan that regards energy storage as an independent industry and has issued special support policies. Especially in the absence of a payment mechanism for energy storage, the commercialization model of the energy storage industry has not yet taken.

The research and development of new and renewable energy sources and the search for advanced methods to improve energy efficiency have become the primary issues of global concern. For a large energy production and consumption country such as China, there is both the need for energy saving and emission reduction, as well as the need for energy growth to support economic development, which requires vigorous development of the energy storage industry.

The analysis report shows that the increasing energy consumption, especially the impact of the massive use of fossil fuels such as coal and petroleum on the environment and the global climate has made human sustainable development goals face serious threats. It is predicted that, based on the current technology for mining non-renewable energy and the continuous consumption rate of these fossil fuels day and night, the useful life of coal, natural gas and oil is $100-120$ years, 30 - 50 years and 18 respectively -30 years. Obviously, the biggest problem and dilemma facing the 21st century may not be war and food, but energy (Zhou et al., 2020).

Energy storage is divided into chemical energy storage and mechanical energy storage in terms of methods. The most widely used in chemical energy storage is battery energy storage. Lead-acid batteries are generally used in high-power occasions, which are mainly used for the storage of surplus energy in emergency power supplies, battery cars, and power plants. Low-power occasions can also use rechargeable dry batteries such as nickel-metal hydride batteries, lithium-ion 
batteries, etc. It also includes capacitor energy storage, which has been widely studied in recent years. A capacitor is also an energy storage element, and its stored energy is proportional to the square of its capacitance and terminal voltage. Capacitor energy storage is easy to maintain and does not require superconductors. Another important point of capacitor energy storage is that it can provide instantaneous high power, which is very suitable for laser, flash and other applications. Mechanical energy storage such as compressed air energy storage and flywheel energy storage are still in the research stage.

The demand for energy storage is mainly based on the following two aspects.

The rapid development of the wind power photovoltaic industry will promote the development of the large-capacity energy storage industry. Energy storage technology largely solves the problem of randomness and volatility of new energy power generation, can achieve smooth output of new energy power generation, can effectively adjust the changes in grid voltage, frequency and phase caused by new energy power generation, making large-scale wind power and photovoltaic power generation are conveniently and reliably integrated into conventional power grids. The future of energy storage batteries should be in the wind power and optoelectronics industries, especially the wind power industry that has been deployed in large numbers. Wind resources are unstable, and in the middle of the night, when wind resources are relatively large, electricity consumption is low. Therefore, despite the rapid development of the wind and photovoltaic industries in recent years, they have been plagued by the word grid connection and energy storage technology. Application can help smooth wind farm output and fill valleys with peaks.

\section{Prospect of Energy Storage}

The good development of new energy vehicles, especially electric vehicles, is good for the development of power battery energy storage industry. Energy storage technology can be said to be the core of the new energy industry revolution. The huge development potential of the energy storage industry will inevitably lead to fierce competition in this market. If policies are put in place, my country's energy storage industry can quickly grow into an emerging strategic industry with important global influence, and it will greatly promote the large-scale development of domestic new energy (Ma et al., 2016).

In recent years, the state has formulated various support policies in the field of new energy development and application to support the development of the new energy industry. The rapid development of the industry has put forward a corresponding demand for technical talents. With the encouragement of the Ministry of Education, domestic universities have opened technical specialties related to the application of new energy. The teaching direction of new energy majors that have been established so far mainly focuses on the field of new energy power generation. However, the development of the new energy industry requires the balance between power generation and energy storage system development. In recent years, new energy vehicles have also achieved rapid development, and 
the core component restricting their development is still the energy storage system. Therefore, it is necessary to develop energy storage applications and technical directions based on the professional background of new energy application technology in colleges and universities.

For industry needs, China's new energy electric vehicle industry began at the beginning of the 21st century. In 2008, new energy vehicles showed a comprehensive attack in China and became my country's "first year of new energy vehicles". In the cold winter of the auto market in 2018, according to the statistics of the China Automobile Association, the production and sales of new energy vehicles were 1.27 million and 1.256 million, respectively, an increase of 59.9\% and $61.7 \%$ over the same period of the previous year. In January-August 2019, the production and sales of new energy vehicles were completed at 799,000 units and 793,000 units, an increase of $31.6 \%$ and $32.0 \%$ respectively over the same period last year. The development of new energy vehicles is inseparable from its core component, the battery. Compared with other commercial rechargeable batteries, lithium-ion batteries have the advantages of high energy density, long cycle life, wide operating temperature range, and safety and reliability. And for the cruising range, it is also a $48 \mathrm{~V}$ battery. When fully charged, the cruising range of a lithium battery electric vehicle is relatively one-third higher than that of a lead-acid battery, with a larger capacity and a longer range.

At present, the domestic new energy power generation and energy storage related industries are in a period of rapid development. Based on the new energy application technology professional background, the construction of energy storage and application technology direction is carried out, which meets the development needs of the new energy industry and can ensure the energy chemical major Students achieve flexible and efficient employment and increase the employment rate.

"Proposal of the Central Committee of the Communist Party of China on Formulation of the 13th Five-Year Plan for National Economic and Social Development" clearly states that it supports the development of emerging industries such as energy conservation, environmental protection, and new energy. The needs of industrial development and the guidance of national policies will ensure the orderly development of new energy storage and application technology (Hao et al., 2015).

\section{Necessity of Building New Energy Storage and Application Technology}

In recent years, the country has strongly supported the development of the new energy industry, and the new energy automobile industry and its industrial chain have also achieved rapid development. The rapid development of the industry needs the support of relevant technical talents. Based on the background of new energy application technology, the development of new energy storage and application technology direction meets the national medium- and long-term planning requirements. Therefore, it is necessary to build a new energy storage 
and application technology direction in the Energy Chemical Industry (Huang \& Xiao, 2018).

1) The direction of developing energy storage and application technology meets the needs of national energy conservation, environmental protection and sustainable development. With the increasing depletion of non-renewable energy sources, world powers have repositioned their energy reserves. In recent years, China has vigorously developed the new energy industry and promoted the concept of low-carbon energy-saving and environmental protection. In the development of the new energy industry, the matching energy storage system has increasingly exposed shortcomings, which has become one of the key problems that need to be solved urgently. In addition, energy shortage and environmental pollution are two of the most difficult problems in the world today. Fuel-powered transportation vehicles have become an important part of energy shortages and environmental pollution. Practice in recent years has shown that the use of secondary batteries as pure power or hybrid power in the medium and long term is an inevitable choice for solving energy shortages and environmental pollution. Carrying out teaching and research on energy storage and applied technology in colleges and universities to provide technical-skilled talents for the development of the industry is conducive to promoting the development of my country's new energy industry and meets the needs of national energy conservation and environmental protection and sustainable development.

2) The development of energy storage and application technology is the need to increase the employment rate and realize the life value of students. Compared with the traditional employment in energy and chemical industries, new energy and its energy storage system, which is a new employment direction, have policy advantages, and related industries have developed rapidly. The cultivation of talents is far from meeting the needs of industrial development. Through the construction of new energy storage and application technology, teaching and research in the field of energy storage are carried out to cultivate and reserve relevant technical talents for the country. On the one hand, it can provide talent support for the development of the national new energy industry. On the other hand, energy storage in the energy field provides students with a broad employment space, so that students can apply the skills they have learned to the country. Therefore, the teaching and practical training of energy storage and applied technology courses will help increase the employment rate of students, and also realize the life value of students.

3) The development of energy storage and application technology is the need for the professional development of energy and chemical industry. In the energy and chemical industry, power generation technology and energy storage technology are matching technologies. After the new energy generates electricity, the generated electricity needs to be stored and utilized by the energy storage system. However, in the current process of building new energy majors in colleges and universities, emphasis is placed on the teaching of power generation and the teaching of energy storage is ignored. At present, according to the situation of 
new energy professional construction, the field of power generation is relatively mature and has a certain scale, so the follow-up new energy professional construction should be developed in the field of energy storage and moderately inclined. Under the background of new energy major, develop new energy storage and application technology direction, improve the curriculum system planning and construction, meet the development needs of new energy application technology major. New energy storage and application technology curriculum system should include professional basic courses, professional basic skills and professional core skills, of which professional core skills courses should be based on the existing new energy storage industry involved position setting, and professional basic skills and professional basic courses are set according to the basic knowledge and basic skills involved in professional core skills.

\section{Acknowledgements}

Supported by "Teaching Support Program for Outstanding Young Teachers of North China Electric Power University”.

\section{Conflicts of Interest}

The authors declare no conflicts of interest regarding the publication of this paper.

\section{References}

Hao, X., Zhang, W., Duan, Z., Li, J., \& Zhang, Z. (2015). Exploration and Practice of Talents Training Mode for the Plan of Outstanding Engineers with Characteristics of Energy Chemical Industry. Higher Education in Chemical Engineering, 1, 18-22.

Huang, Z., \& Xiao, W. (2018). Development of Energy Storage and Application Technology Based on the Background of New Energy Application Technology. Guangdong Education (Vocational Education), 2, 31-33.

Ma, X., Gui, L., Tang, Y., Li, J., \& Guo, Q. (2016). Teaching Reform and Practice of Energy Chemical Engineering Course. Chinese Journal of Chemical Education, 10, 57-59.

Peng, X., \& Ye, J. (2020). Innovation Promoting the Development of Higher Education for Chemical Engineering. Higher Education in Chemical Engineering, 1, 1-7.

Zhou, Y., Lu, Y., Hu, X., Han, L., \& Liu, P. (2020). Discussions on Teaching Reform of Chemical Engineering Based on Multi-Level Process Intensification. Higher Education in Chemical Engineering, 2, 84-87. 